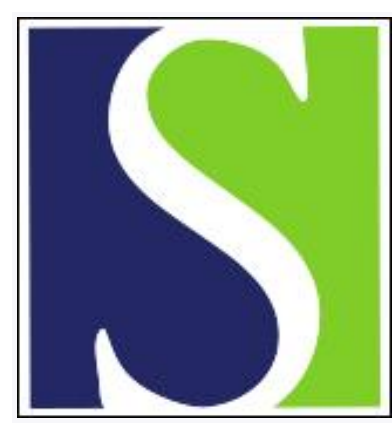

Scand J Work Environ Health 1999;25(4):317-325

https://doi.org/10.5271/sjweh.441

Issue date: Aug 1999

Mortality from nonmalignant diseases of the respiratory, genitourinary and nervous systems among workers exposed to styrene in the reinforced plastics and composites industry in the United States

by Wong $\mathrm{O}$, Trent $\mathrm{LS}$

Key terms: cohort study; epidemiology; occupational health

This article in PubMed: www.ncbi.nlm.nih.gov/pubmed/10505657 


\title{
Mortality from nonmalignant diseases of the respiratory, genitourinary and nervous systems among workers exposed to styrene in the reinforced plastics and composites industry in the United States
}

\author{
by Otto Wong, $S c D,{ }^{1,2}$ Lisa $S$ Trent, MS
}

\begin{abstract}
Wong 0, Trent LS. Mortality from nonmalignant diseases of the respiratory, genitourinary and nervous systems among workers exposed to styrene in the reinforced plastics and composites industry in the United States. Scand $J$ Work Environ Health 1999;25(4):317-325.
\end{abstract}

\begin{abstract}
Objectives Mortality from diseases of the nervous system and nonmalignant diseases of the respiratory and genitourinary systems was examined for workers exposed to styrene.

Methods Altogether 15826 styrene-exposed workers in 30 plants in the reinforced plastics and composites industry were included. Vital status was ascertained through 31 December 1989. Individual exposure estimates were developed based on job functions, existing industrial hygiene data, process changes, engineering controls, work practices, and the use of personal protective equipment. Analyses were based on cause-specific standardized mortality ratios (SMR) and the Cox proportional hazards model. Mortality data were analyzed by latency, duration of exposure, average exposure, cumulative exposure, and process category.

Results For diseases of the nervous system, the SMR was 0.56 [95\% confidence interval (95\% CI) $0.31-0.95$ ]. Mortality from nonmalignant genitourinary diseases was not increased (SMR 0.87, 95\% CI 0.46-1.50). Latency, duration of exposure, average exposure, cumulative exposure, and process category showed no association between styrene exposure and these 2 types of disease. A small increase in mortality from nonmalignant respiratory diseases was found (SMR 1.21, 95\% CI 0.98-1.47), mainly due to "other nonmalignant respiratory diseases" (SMR 1.40, $95 \%$ CI 1.04 1.84). The highest increase occurred for short exposure duration (SMR 1.79 for $<1$ year's exposure) or low exposure (SMR 2.15 for $<10$ ppm-years); there were no increased risks in the high exposure categories. The Cox proportional hazard model revealed no association between styrene exposure and the diseases.

Conclusions No relationship was found between mortality from any of the diseases examined and any of the styrene exposure indices. The findings were compared with those reported in a European study of styrene-exposed workers.
\end{abstract}

Key terms cohort study, epidemiology, occupational health.

Currently there are 2 large-scale mortality cohort studies of workers exposed to styrene, the European study conducted by the International Agency for Research on Cancer (IARC) and its collaborators and the United States (US) study by Applied Health Sciences. The IARC study was based on a multicentric investigation consisting of several cohorts from Denmark, Finland, Italy, Norway, Sweden, and the United Kingdom $(1,2)$. It consisted of 40683 workers in the reinforced plastics industry in these 6 European countries. According to the investigators, no excess was observed for mortality from all causes, all cancers, lung cancer, or other major epithelial cancers (1, 2). Mortality from neoplasms of the lymphatic and hematopoietic tissues was also not elevated. In the 1993 or 1994 report (1, 2), Kogevinas et al reported no increased mortality from mental disorders [standardized mortality ratio (SMR) 1.07], diseases of the nervous system (SMR 0.79 ), diseases of the respiratory system (SMR 0.81), or diseases of the genitourinary system (SMR 0.97).

In 1996, 3 papers based on the IARC study were published by Welp et al (3-5), reporting mortality analyses from nonmalignant respiratory diseases, nonmalignant

1 Applied Health Sciences, Inc, San Mateo, California, United States.

2 Department of Epidemiology, School of Public Health, Tulane University Medical Center, New Orleans, Louisiana, United States.

Reprint requests to: Otto Wong, Applied Health Sciences, Inc, 181 Second Avenue, Suite 628, PO Box 2078, San Mateo, California 94401, USA. [E-mail: ottowong@aol.com] 
genitourinary diseases, diseases of the nervous system, and mental disorders. For nonmalignant respiratory diseases, Welp et al (3) drew the following conclusion: "Mortality from pneumonia was associated with intensity of exposure to styrene, but this may have been due to chance. Mortality from bronchitis, emphysema, and asthma was not associated with styrene exposure [p 499]". With regard to nonmalignant genitourinary diseases, it was concluded that mortality "increased as the average intensity of exposure increased [p 226]" (4). The authors also commented that "This finding indicates that other data should be scrutinized [p 223]." Finally, Welp and her colleagues (5) reported that "mortality from diseases of the central nervous system increased with time since first exposure, duration of exposure, average level of exposure, and cumulative exposure to styrene [p 623]." The increase in mortality from the central nervous system was primarily influenced by the increased mortality from epilepsy. Welp et al stated that "mortality from epilepsy increased monotonically with all styrene exposure indicators, while associations for degenerative diseases of the central nervous system were generally weaker [p 623]". The authors concluded that "These findings suggest that, in addition to the known acute effects, exposure to styrene may contribute to chronic diseases of the central nervous system [p 623]".

The other large-scale mortality study was based on workers in the United States (6). Mortality of a cohort of 15826 male and female workers exposed to styrene at 30 participating plants in the reinforced plastics and composites industry in the United States has recently been updated and reported by Wong et al (7). The primary analyses were conducted using the University of Pittsburgh OCMAP program, which provided a standard set of causes of death. Except for nonmalignant respiratory diseases, causes of death discussed in the 1996 papers by Welp et al were not part of the standard OCMAP analysis, and, therefore, not presented for the US cohort in the Wong et al (7) report. The present report summarizes new analyses for mortality from diseases of the nervous system, nonmalignant diseases of the respiratory system, and nonmalignant diseases of the genitourinary system in the US cohort.

\section{Subjects and methods}

The cohort consisted of 15826 male and female employees at 30 reinforced plastics plants in the United States. To be included in the cohort, an employee must have worked in areas with styrene exposure for a minimum of 6 months between 1 January 1948 and 31 December 1977. The vital status of the cohort was ascertained through 31 December 1989. Sources of vital status information included personnel records maintained at the participating plants, the Death Master File of the Social Security Administration, the National Death Index of the National Center for Health Statistics, and the data base of a commercial retail credit bureau. With the use of information from these sources, death certificates were obtained from individual state health departments. Causes of death were coded according to the revision of the International Classification of Diseases (ICD) in effect at the time of death.

Person-years of observation started after 6 months of exposure to styrene and ended on the date of death or 31 December 1989, whichever was earlier. For those lost to follow-up (unknown vital status), person-years were counted up to the last date of contact. Person-years were classified by age (5-year groups), gender, and calendar years (5-year groups). Expected deaths were based on US national age- gender- cause- race- and year-specific death rates, and cause-specific standardized mortality ratios (SMR) were computed using the University of Pittsburgh OCMAP computer program. Since mortality rates for the causes of death included in our report are not part of the regular mortality rates in the OCMAP program, the rates were requested from the University of Pittsburgh. Because race information was missing from employment records for most of the cohort, the entire cohort was assumed to be white (7).

The Cox proportional hazards model was also used in the analysis. One important advantage of the Cox model was that the actual exposure data could be used instead of grouped data. An additional advantage was that only internal cohort data were used, whereas SMR values were based on comparisons with an external population. The actual computation was performed using SAS PHREG software. The independent variables used in these models included age, gender, duration of exposure, average exposure, and cumulative exposure.

The 30 reinforced plastics plants in the study manufactured various products, including sheet molding compounds, bulk molding compounds, tanks, pipes, ducts, boats, panels, auto-parts, trays, and small miscellaneous parts. The first year of styrene exposure at the individual plants ranged from 1948 to 1968 . At the time of the original epidemiologic study, a parallel exposure assessment investigation was conducted $(6,7)$.

The exposure classification scheme used in the study was developed in several stages. First, for each plant, a list of job titles was generated based on employment records collected in the study. This list consisted of job or department (or location) titles or both as they appeared in the personnel records. The initial list consisted of a large number of entries, since the same job or department title could have been recorded slightly differently over the years. With assistance from the participating plants, these duplications were consolidated. 
The consolidated list (by plant) was provided to the industrial hygiene team for exposure assessment. Individual plants were visited by a field survey team, and a detailed industrial hygiene assessment was conducted at each plant to measure current (around 1980) exposure levels of styrene and other substances. Information on job functions, work practices, past industrial hygiene measurements, process changes and modifications, engineering controls, and personal protection equipment at each plant was also obtained. Using the information collected, the industrial hygienists developed a list of 19 job categories with homogeneous exposures. Each job title was assigned to 1 of the 19 job categories.

A job-exposure matrix was developed for each plant, and a current 8-hour time-weighted-average (8-hour TWA) and an exposure range were assigned to each job category. Based on information on changes over time, historical TWA values were likewise estimated. Job categories in which typical TWA estimates for styrene were low included finish and assembly ( $5 \mathrm{ppm})$, storage and shipping $(5 \mathrm{ppm})$, office and other nonproduction (2 $\mathrm{ppm})$, injection molding (4 ppm), field service (5 ppm), preform production ( $7 \mathrm{ppm}$ ), and pultrusion ( $5 \mathrm{ppm})$. Job categories with moderate TWA values ( $20-45 \mathrm{ppm})$ included molding compound production, gel coating, and winding. A typical styrene exposure in the spray-up or lay-up process category was $60 \mathrm{ppm}$, with a range of 5 to $120 \mathrm{ppm}$ that reflects considerable differences among facilities and the nature of specific work activities. In terms of job titles, on the average, laminators were exposed to the highest levels ( 8 -hour TWA of $80 \mathrm{ppm}$ ). Overall, the average 8-hour TWA values for the majority of jobs was 10 ppm or less.

Two quantitative styrene exposure indices were developed. Based on the employment history of each cohort member (through the end of 1977) and the exposure estimates derived from the job-exposure matrix for that particular plant, a TWA was assigned to each job in a worker's employment history. A cumulative exposure in ppm-years, calculated as the sum of the products of the TWA and duration of exposure of each job, was developed for each cohort member. In order to compare the results to those in the IARC study, an average exposure in parts per million (cumulative exposure divided by duration of exposure) was also calculated for each cohort member.

In addition, based on a consideration of both exposure estimates and processes and job activities, 6 process categories were created, each with a distinct and relatively homogeneous exposure profile to styrene in combination with other chemicals. The 6 process categories are as follows, along with examples of their component job categories: (i) open-mold process (examples: sprayup/lay-up, winding, gel coating, stringing and fitting, laminating), (ii) mixing and closed-mold process (examples: cutting, weighing, pressing, mixing, pultrusion, inject molding, casting), (iii) finish and assembly (examples: finishing, storing and shipping, repairing), (iv) plant office and support (examples: general and nonproduction, quality control, office and others), (v) maintenance and preparation (examples: maintenance, utility, mold preparation), and (vi) supervisory and professional (examples: supervisors' and engineers' tasks).

Table 1 summarizes the descriptive statistics of the cohort. In terms of follow-up, the vital status of only 547 cohort members $(3.5 \%)$ remained unknown at the end of 1989. Of the 1628 workers identified to have died, death certificates were obtained for all but $42(2.56 \%)$. These 42 deaths were included in the overall SMR calculations, which have been reported previously (7), but not in the cause-specific SMR calculations. In terms of exposure, close to one-quarter of the cohort $(23.5 \%)$ had more than $100 \mathrm{ppm}$-years of cumulative exposure, and one-third $(34.2 \%)$ had an average exposure of $20 \mathrm{ppm}$ or higher. It should be pointed out that the employment histories were not updated after 1977, the closing date of the original study. Therefore, all work and exposure assignments were truncated in 1977.

Table 1. Descriptive statistics of the cohort of workers exposed to styrene in the reinforced plastics and composites industry.

\begin{tabular}{|c|c|c|}
\hline \multirow[t]{2}{*}{ Description } & \multicolumn{2}{|c|}{ Workers } \\
\hline & N & $\%$ \\
\hline Total cohort & 15826 & 100.0 \\
\hline Men & 11958 & 75.6 \\
\hline Women & 3868 & 24.4 \\
\hline \multicolumn{3}{|c|}{ Duration of employment (years) as of 31 December 1977} \\
\hline $0.5-0.9$ & 3712 & 23.5 \\
\hline $1.0-1.9$ & 3528 & 22.3 \\
\hline $2.0-4.9$ & 4326 & 27.3 \\
\hline$\geq 5.0$ & 4260 & 26.9 \\
\hline \multicolumn{3}{|c|}{ Cumulative exposure (ppm-years) as of 31 December 1977} \\
\hline$<10.0$ & 3778 & 23.9 \\
\hline $10.0-29.9$ & 4119 & 26.0 \\
\hline $30.0-99.9$ & 4210 & 26.6 \\
\hline$\geq 100.0$ & 3719 & 23.5 \\
\hline \multicolumn{3}{|c|}{ Average intensity of exposure (ppm) from hire to 31 December 1977} \\
\hline$<5.0$ & 2970 & 18.8 \\
\hline $5.0-9.9$ & 3702 & 23.4 \\
\hline $10.0-19.9$ & 3736 & 23.6 \\
\hline $20.0-59.9$ & 3161 & 19.9 \\
\hline$\geq 60.0$ & 2257 & 14.3 \\
\hline \multicolumn{3}{|c|}{ Vital status as of 31 December 1989} \\
\hline Alive & 13651 & 86.2 \\
\hline Dead & 1628 & 10.3 \\
\hline With death certificates & 1586 & 97.4 \\
\hline Without death certificates & 42 & 2.6 \\
\hline Unknown & 547 & 3.5 \\
\hline
\end{tabular}

Scand J Work Environ Health 1999, vol 25, no 4 


\section{Results}

Table 2 shows the observed deaths, SMR values, and $95 \%$ confidence intervals $(95 \% \mathrm{CI}$ ) for selected causes of death for the entire cohort and by latency (time since first exposure). For diseases of the nervous system, there were 14 deaths in the entire cohort, significantly fewer than the 24.7 expected. The corresponding SMR was 0.56 (95\% CI $0.31-0.95$ ). Only 2 deaths in the cohort were attributed to epilepsy, comparable to the 2.7 expected (SMR 0.73, 95\% CI 0.09-2.66). For diseases of the genitourinary system, there were 13 observed deaths, comparable to the 14.8 expected (SMR $0.87,95 \%$ CI $0.46-$ 1.50 ). There were only 2 deaths from nephritis, slightly fewer than the 3.7 expected (SMR 0.54, 95\% CI 0.061.96). Altogether 97 deaths were coded as nonmalignant respiratory diseases, more than the expected 80.2. However, the increase was not statistically significant (SMR $1.21,95 \%$ CI $0.98-1.47$ ). Within the broad category of nonmalignant respiratory diseases, 23 deaths were from pneumonia, comparable to the 24.9 expected (SMR 0.92, 95\% CI 0.58 - 1.38). For the subcategory "bronchitis, emphysema and asthma," there were 23 deaths, slightly more than the 18.1 expected (SMR $1.27,95 \%$ CI $0.80-$ 1.91). There was a statistically significant increase in mortality for the subcategory "other nonmalignant respiratory diseases." A total of 51 deaths in the subcategory were observed, compared with 36.3 expected (SMR $1.40,95 \%$ CI 1.04-1.84). Thirty-six of these deaths (71\%) were from "chronic airway obstruction, not otherwise specified" (9th ICD 496), which included "chronic nonspecific lung disease," "chronic obstructive lung disease," and "chronic obstructive pulmonary disease, not otherwise specified."

Although not shown in table 2, an analysis was also performed separately by gender. All 14 deaths from diseases of the nervous system in the cohort occurred among the male workers, compared with 19.5 expected (SMR $0.71,95 \%$ CI $0.39-1.20$ ). Among the women, no death was attributed to diseases of the nervous system, whereas 5.1 were expected. Another cause of death for which the 2 genders differed was nonmalignant respiratory diseases. For the men, the SMR for nonmalignant respiratory diseases was 1.24 ( 84 observed, $95 \%$ CI $0.98-1.53$ ), whereas that for the women was 1.04 (13 observed, 95\% CI $0.55-1.78$ ). For other causes of death, mortality was similar between the 2 genders.

Mortality analysis by latency (time since first exposure to styrene) is also presented in table 2 . The increase in mortality from nonmalignant respiratory diseases was the most prominent 20 years after the first exposure (SMR 1.44, 95\% CI 1.05-1.92), whereas there was no increase within the first 10 years (SMR 0.65, 95\% CI $0.32-1.17)$. In the group with a latency of $10-19$ years, the SMR for nonmalignant respiratory diseases was 1.27 (95\% CI 0.90-1.73)

Table 3 depicts mortality by duration of exposure. Short-term workers with less than 1 year of exposure had the highest mortality from nonmalignant respiratory diseases (SMR 1.41, 95\% CI 0.86-2.18), whereas for those with at least 10 years of exposure there was no increase (SMR 0.97, 95\% CI 0.57-1.54). No significant increase was observed for any specific causes of death in any of the groups by duration of exposure. No pattern by length of exposure was evident for any specific causes of death in table 3. In particular, among those with 10 or more years of exposure, no increased mortality was seen with the exception of nonmalignant genitourinary diseases. Six such deaths were observed among those with 10 or more years of exposure (SMR 2.04, 95\% CI $0.74-4.44)$. However, the increase was not statistically significant. A similar analysis based on length of employment was also performed (not shown). The results were very similar, indicating that length of employment and length of exposure were the same or very similar for most of the cohort members.

The results of the analysis by cumulative exposure are shown in table 4. For mortality from diseases of the nervous system, no increase or pattern was seen with regard to cumulative exposure. For mortality from nonmalignant respiratory diseases, a significant increase was observed among those with less than 10.0 ppm-years of

Table 2. Observed deaths $(0)$ in the entire cohort and the standardized mortality ratios (SMR) with their $95 \%$ confidence intervals (95\% C1) for selected causes by time since first exposure to styrene.

\begin{tabular}{|c|c|c|c|c|c|c|c|c|c|c|c|c|}
\hline \multirow[t]{2}{*}{ Cause of death } & \multicolumn{3}{|c|}{$<10$ years } & \multicolumn{3}{|c|}{$10-19$ years } & \multicolumn{3}{|c|}{$\geq 20$ years } & \multicolumn{3}{|c|}{ Total } \\
\hline & 0 & SMR & $95 \% \mathrm{Cl}$ & 0 & SMR & $95 \% \mathrm{Cl}$ & 0 & SMR & $95 \% \mathrm{Cl}$ & 0 & SMR & $95 \% \mathrm{Cl}$ \\
\hline Diseases of the nervous system & 1 & 0.10 & $0.00-0.57$ & 6 & 0.68 & $0.25-1.49$ & 7 & 1.13 & $0.45-2.33$ & 14 & 0.56 & $0.31-0.95$ \\
\hline Epilepsy & - & 0 & . & 1 & 1.00 & $0.02-5.59$ & 1 & 2.84 & $0.07-15.84$ & 2 & 0.73 & $0.09-2.66$ \\
\hline Nonmalignant respiratory diseases & 11 & 0.65 & $0.32-1.17$ & 40 & 1.27 & $0.90-1.73$ & 46 & 1.44 & $1.05-1.92$ & 97 & 1.21 & $0.98-1.47$ \\
\hline Pneumonia & 3 & 0.44 & $0.09-1.31$ & 8 & 0.84 & $0.36-1.65$ & 12 & 1.38 & $0.71-2.41$ & 23 & 0.92 & $0.58-1.38$ \\
\hline Bronchitis, emphysema and asthma & 6 & 1.26 & $0.46-2.75$ & 7 & 0.96 & $0.38-1.98$ & 10 & 1.65 & $0.79-3.03$ & 23 & 1.27 & $0.80-1.91$ \\
\hline Other nonmalignant respiratory diseases & 2 & 0.39 & $0.04-1.44$ & 25 & 1.74 & $1.13-2.57$ & 24 & 1.41 & $0.90-2.10$ & 51 & 1.40 & $1.04-1.84$ \\
\hline Nonmalignant genitourinary diseases & 1 & 0.23 & $0.01-1.30$ & 8 & 1.45 & $0.62-2.86$ & 4 & 0.79 & $0.21-2.03$ & 13 & 0.87 & $0.46-1.50$ \\
\hline Nephritis & - & 0 & . & 2 & 1.70 & $0.20-6.17$ & - & 0 & & 2 & 0.54 & $0.06-1.96$ \\
\hline
\end{tabular}


exposure (SMR 1.64, 95\% CI 1.09-2.37), whereas no statistically significant increase was evident among those with more than 100.0 ppm-years of exposure (SMR 1.04, $95 \%$ CI $0.66-1.57)$. The increased mortality from nonmalignant respiratory diseases among those with a cumulative exposure of less than $10.0 \mathrm{ppm}$-years came from the 2 subcategories "bronchitis, emphysema and asthma" (SMR 2.07, 95\% CI 0.89-4.08) and "other nonmalig- nant respiratory diseases" (SMR 2.15, 95\% CI 1.233.49). Only the latter was statistically significant. There was a nonsignificant increase in mortality from nonmalignant genitourinary diseases among the workers with $\geq 100$ ppm-years of exposure ( 5 observed, 3.7 expected, SMR $1.34,95 \%$ Cl $0.43-3.13$ ).

Table 5 shows the mortality analysis by average intensity of styrene exposure. The category nonmalignant

Table 3. Observed deaths (0) in the entire cohort and the standardized mortality ratios (SMR) with their $95 \%$ confidence intervals (95\% Cl) for selected causes by duration of exposure to styrene.

\begin{tabular}{|c|c|c|c|c|c|c|c|c|c|c|c|c|c|c|c|}
\hline \multirow[t]{2}{*}{ Cause of death } & \multicolumn{3}{|c|}{$<1.0$ year } & \multicolumn{3}{|c|}{$1.0-1.9$ years } & \multicolumn{3}{|c|}{$2.0-4.9$ years } & \multicolumn{3}{|c|}{$5.0-9.9$ years } & \multicolumn{3}{|c|}{$\geq 10.0$ years } \\
\hline & 0 & SMR & $95 \% \mathrm{Cl}$ & 0 & SMR & $95 \% \mathrm{Cl}$ & 0 & SMR & $95 \% \mathrm{Cl}$ & 0 & SMR & $95 \% \mathrm{Cl}$ & 0 & SMR & $95 \% \mathrm{Cl}$ \\
\hline \multicolumn{16}{|l|}{ Diseases of the } \\
\hline nervous system & 1 & 0.18 & $0.01-1.05$ & 4 & 0.82 & $0.22-2.11$ & 3 & 0.47 & $0.09-1.38$ & 2 & 0.46 & $0.05-1.68$ & 4 & 1.03 & $0.28-2.64$ \\
\hline Epilepsy & 1 & 1.36 & $0.03-7.60$ & - & 0 & . & - & 0 & & 1 & 2.59 & $0.06-14.46$ & - & 0 & . \\
\hline \multicolumn{16}{|l|}{ Nonmalignant } \\
\hline respiratory diseases & 20 & 1.41 & $0.86-2.18$ & 17 & 1.25 & $0.73-2.01$ & 22 & 1.18 & $0.74-1.79$ & 20 & 1.29 & $0.79-2.00$ & 18 & 0.97 & $0.57-1.54$ \\
\hline $\begin{array}{l}\text { Pneumonia } \\
\text { Bronchitis, emphysema }\end{array}$ & 3 & 0.62 & $0.12-1.83$ & 6 & 1.36 & $0.50-2.97$ & 6 & 0.98 & $0.36-2.14$ & 3 & 0.65 & $0.13-1.92$ & 5 & 0.98 & $0.32-2.30$ \\
\hline $\begin{array}{l}\text { and asthma } \\
\text { Other nonmalignant }\end{array}$ & 6 & 1.95 & $0.71-4.26$ & 3 & 0.99 & $0.20-2.90$ & 4 & 0.94 & $0.25-2.41$ & 6 & 1.68 & $0.61-3.66$ & 4 & 0.96 & $0.26-2.46$ \\
\hline respiratory diseases & 11 & 1.79 & $0.89-3.21$ & 8 & 1.34 & $0.58-2.65$ & 12 & 1.49 & $0.77-2.61$ & 11 & 1.54 & $0.77-2.76$ & 9 & 0.99 & $0.45-1.88$ \\
\hline $\begin{array}{l}\text { Nonmalignant } \\
\text { genitourinary diseases }\end{array}$ & 1 & & & & 0 & & & 0.82 & $0.17-241$ & 3 & 110 & $0 ? ?-$ & 6 & 204 & -4.44 \\
\hline Nephritis & - & $\begin{array}{r}0.04 \\
0\end{array}$ & $\frac{0.01-1.93}{.}$ & - & 0 & $\dot{.}$ & 1 & $\begin{array}{l}0.02 \\
1.02\end{array}$ & $0.02-5.73$ & - & 0 & & $\begin{array}{l}0 \\
1\end{array}$ & $\begin{array}{l}2.04 \\
1.94\end{array}$ & $0.04-10.82$ \\
\hline
\end{tabular}

Table 4. Observed deaths $(0)$ in the entire cohort and the standardized mortality ratios (SMR) with their $95 \%$ confidence intervals ( $95 \%$ $\mathrm{Cl})$ for selected causes by cumulative exposure to styrene.

\begin{tabular}{|c|c|c|c|c|c|c|c|c|c|c|c|c|}
\hline \multirow[t]{2}{*}{ Cause of death } & \multicolumn{3}{|c|}{$<10.0$ ppm-years } & \multicolumn{3}{|c|}{$10.0-29.9$ ppm-years } & \multicolumn{3}{|c|}{$30.0-99.9$ ppm-years } & \multicolumn{3}{|c|}{$\geq 100.0$ ppm-years } \\
\hline & 0 & SMR & $95 \% \mathrm{Cl}$ & 0 & SMR & $95 \% \mathrm{Cl}$ & 0 & SMR & $95 \% \mathrm{Cl}$ & 0 & SMR & $95 \% \mathrm{Cl}$ \\
\hline Diseases of the nervous system & 3 & 0.49 & $0.10-1.45$ & 2 & 0.32 & $0.04-1.18$ & 6 & 0.87 & $0.32-1.90$ & 3 & 0.53 & $0.10-1.54$ \\
\hline Epilepsy & 1 & 1.42 & $0.03-7.96$ & - & 0 & . & 1 & 1.38 & $0.03-7.71$ & - & 0 & . \\
\hline Nonmalignant respiratory diseases & 28 & 1.64 & $1.09-2.37$ & 17 & 0.94 & $0.54-1.51$ & 29 & 1.25 & $0.84-1.80$ & 23 & 1.04 & $0.66-1.57$ \\
\hline Pneumonia & 4 & 0.72 & $0.19-1.84$ & 7 & 1.18 & $0.47-2.44$ & 9 & 1.26 & $0.57-2.40$ & 3 & 0.47 & $0.09-1.38$ \\
\hline Bronchitis, emphysema and asthma & 8 & 2.07 & $0.89-4.08$ & 5 & 1.24 & $0.40-2.89$ & 4 & 0.76 & $0.20-1.95$ & 6 & 1.22 & $0.44-2.65$ \\
\hline Other nonmalignant respiratory diseases & 16 & 2.15 & $1.23-3.49$ & 5 & 0.63 & $0.20-1.48$ & 16 & 1.52 & $0.87-2.47$ & 14 & 1.33 & $0.72-2.23$ \\
\hline Nonmalignant genitourinary diseases & 1 & 0.30 & $0.01-1.67$ & 4 & 1.13 & $0.30-2.90$ & 3 & 0.71 & $0.14-2.07$ & 5 & 1.34 & $0.43-3.13$ \\
\hline Nephritis & - & 0 & . & 1 & 1.05 & $0.02-5.88$ & 1 & 0.97 & $0.02-5.45$ & - & 0 & . \\
\hline
\end{tabular}

Table 5. Observed deaths $(0)$ in the entire cohort and the standardized mortality ratios (SMR) with their $95 \%$ confidence intervals (95\% Cl) for selected causes by average exposure to styrene.

\begin{tabular}{|c|c|c|c|c|c|c|c|c|c|c|c|c|c|c|c|}
\hline \multirow[t]{2}{*}{ Cause of death } & \multicolumn{3}{|c|}{$<5.0 \mathrm{ppm}$} & \multicolumn{3}{|c|}{$5.0-9.9 \mathrm{ppm}$} & \multicolumn{3}{|c|}{$10.0-19.9 \mathrm{ppm}$} & \multicolumn{3}{|c|}{$20.0-59.9 \mathrm{ppm}$} & \multicolumn{3}{|c|}{$\geq 60.0 \mathrm{ppm}$} \\
\hline & 0 & SMR & $95 \% \mathrm{Cl}$ & 0 & SMR & $95 \% \mathrm{Cl}$ & 0 & SMR & $95 \% \mathrm{Cl}$ & 0 & SMR & $95 \% \mathrm{Cl}$ & 0 & SMR & $95 \% \mathrm{Cl}$ \\
\hline \multicolumn{16}{|l|}{ Diseases of the } \\
\hline nervous system & 2 & 0.35 & $0.04-1.26$ & 4 & 0.61 & $0.16-1.57$ & 5 & 0.79 & $0.25-1.84$ & 2 & 0.48 & $0.05-1.74$ & 1 & 0.50 & $0.01-2.81$ \\
\hline Epilepsy & - & 0 & . & - & 0 & , & 2 & 2.95 & $0.35-10.68$ & - & 0 & & - & 0 & \\
\hline \multicolumn{16}{|l|}{ Nonmalignant } \\
\hline respiratory diseases & 33 & 1.69 & $1.16-2.37$ & 16 & 0.75 & $0.43-1.23$ & 26 & 1.26 & $0.82-1.85$ & 16 & 1.17 & $0.67-1.91$ & 6 & 1.10 & $0.40-2.39$ \\
\hline $\begin{array}{l}\text { Pneumonia } \\
\text { Bronchitis, emphysema }\end{array}$ & 7 & 1.16 & $0.46-2.39$ & 4 & 0.61 & $0.16-1.51$ & 6 & 0.95 & $0.35-2.08$ & 4 & 0.93 & $0.25-2.38$ & 2 & 1.10 & $0.13-4.00$ \\
\hline $\begin{array}{l}\text { and asthma } \\
\text { Other nonmalignant }\end{array}$ & 10 & 2.24 & $1.07-4.12$ & 3 & 0.62 & $0.12-1.82$ & 4 & 0.85 & $0.23-2.18$ & 6 & 2.03 & $0.74-4.41$ & - & 0 & \\
\hline respiratory diseases & 16 & 1.81 & $1.03-2.94$ & 9 & 0.94 & $0.43-1.79$ & 16 & 1.71 & $0.98-2.78$ & 6 & 0.97 & $0.35-2.11$ & 4 & 1.64 & $0.44-4.20$ \\
\hline Nonmalignant & & & & & & & & & & & & & & & \\
\hline genitourinary diseases & 2 & 0.57 & $0.06-2.05$ & 5 & 1.27 & $0.41-2.97$ & 4 & 1.05 & $0.28-2.70$ & 1 & 0.39 & $0.01-2.20$ & 1 & 0.94 & $0.02-5.26$ \\
\hline Nephritis & - & 0 & & 2 & 1.97 & $0.23-7.14$ & - & 0 & & - & 0 & . & - & 0 & . \\
\hline
\end{tabular}


Table 6. Observed deaths (0) and the standardized mortality ratios (SMR), with their $95 \%$ confidence intervals $(95 \% \mathrm{Cl})$ for selected causes by major processing categories. ${ }^{a}$

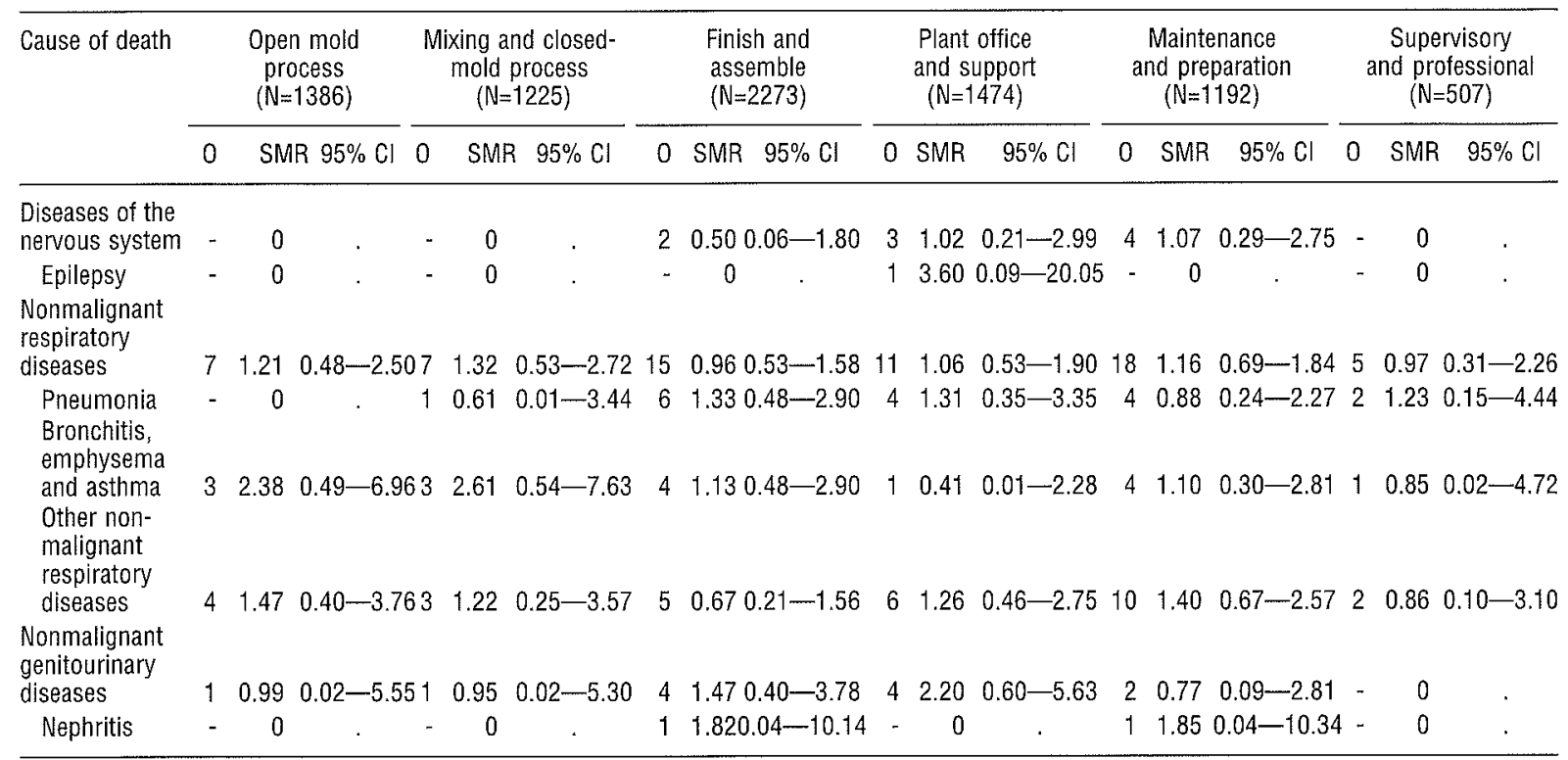

a Workers could be included in more than one category.

Table 7. Analysis of selected causes of death based on the Cox proportional hazards model, with age, gender, and cumulative exposure as independent variables.

\begin{tabular}{|c|c|c|c|}
\hline $\begin{array}{l}\text { Cause of death } \\
\text { (N) }\end{array}$ & $\begin{array}{c}\beta- \\
\text { coefficient }\end{array}$ & SD & P-value \\
\hline \multicolumn{4}{|l|}{ Diseases of the nervous system $(\mathrm{N}=14)$} \\
\hline Age (years) & 0.019 & 0.024 & 0.41 \\
\hline Cumulative exposure (ppm-years) & -0.001 & 0.001 & 0.75 \\
\hline \multicolumn{4}{|c|}{ Nonmalignant genitourinary diseases $(\mathrm{N}=13)$} \\
\hline Age (years) & 0.028 & 0.023 & 0.24 \\
\hline Gender & -0.193 & 0.660 & 0.76 \\
\hline Cumulative exposure (ppm-years) & 0.000 & 0.001 & 0.94 \\
\hline \multicolumn{4}{|l|}{ Nonmalignant respiratory diseases ( $\mathrm{N}=97$ ) } \\
\hline Age (years) & 0.084 & 0.008 & 0.00 \\
\hline Gender & -0.954 & 0.298 & 0.00 \\
\hline Cumulative exposure (ppm-years) & -0.001 & 0.001 & 0.14 \\
\hline \multicolumn{4}{|l|}{ Pneumonia $(\mathrm{N}=23)$} \\
\hline Age (years) & 0.078 & 0.017 & 0.00 \\
\hline Gender & -0.644 & 0.551 & 0.24 \\
\hline Cumulative exposure (ppm-years) & -0.004 & 0.002 & 0.14 \\
\hline
\end{tabular}

respiratory diseases was significantly elevated among workers in the lowest average exposure group $(<5.0$ $\mathrm{ppm}$ ). The increase came from "bronchitis, emphysema and asthma" (SMR 2.24, 95\% CI 1.07-4.12) and from "other nonmalignant respiratory diseases" (SMR 1.81, 95\% CI 1.03-2.94). There was no significant increase in mortality from any of the causes of death examined in any higher categories of average intensity of styrene exposure. Altogether 2257 workers were exposed to an average intensity of more than $60 \mathrm{ppm}$ throughout their employment in the reinforced plastics and composites industry. In this group of workers, there was only 1 death from diseases of the nervous system (SMR 0.50), and no death from epilepsy. In the same group, for nonmalignant respiratory diseases, the SMR was $1.10(95 \% \mathrm{CI}$ $0.40-2.39$ ), and that for "other nonmalignant respiratory diseases" was 1.64 (95\% CI $0.44-4.20)$. For nonmalignant genitourinary diseases, the SMR was $0.94(95 \%$ CI $0.02-5.26$ ).

The mortality analysis by major industrial processing categories is presented in table 6 . A worker was classified into a specific processing category if he or she spent at least 2 years in that category. Therefore, a worker could be classified into more than 1 category. No significant increase in mortality from any cause of death included in table 6 was found for any of the industrial processing categories.

In addition to the indirect method of standardization (SMR values), the data were also analyzed using the Cox proportional hazards model (tables 7 and 8). The following 4 causes of death were selected for this analysis: diseases of the nervous system, nonmalignant genitourinary diseases, nonmalignant respiratory diseases, and pneumonia. The independent variables included in the models in table 7 consisted of age, gender, and cumulative exposure. For diseases of the nervous system, gender was not included in the model because all 14 deaths from this cause occurred among the male workers. As indicated in table 7, cumulative exposure to styrene was not associated with an increased risk of mortality from any of the diseases examined. The models in table 8 included 2 additional exposure indices as independent variables: duration of exposure and average intensity of exposure. No significant increase in mortality from any of the 
4 causes of death was seen in relation to any of the 3 styrene exposure indices: duration, average intensity, or cumulative exposure.

\section{Discussion}

This report is based on data from a previous study of workers in the reinforced plastics and composites industry in the United States $(6,7)$. The analysis presented in the report was stimulated by the recent papers of Welp et al (3-5), which reported mortality from diseases of the nervous system, nonmalignant respiratory diseases, and nonmalignant genitourinary diseases, as well as some of the subcategories within these 3 broad categories, in a study of workers exposed to styrene in Europe. Most of these diseases have not been reported previously in the US cohort.

For the broad category of nonmalignant respiratory diseases, Welp and her colleagues (3) found a significant deficit for the IARC study overall (SMR 0.81, 95\% CI $0.67-0.96$ ). However, they (3) found a positive trend by average intensity for mortality from pneumonia $(\mathrm{P}<0.01)$ and a significantly elevated risk of $6.10(95 \%$ CI 1.44-25.8) for an average intensity of $>200 \mathrm{ppm}$.

In the US cohort, we found a nonsignificant increase in mortality from nonmalignant respiratory diseases (SMR 1.21, 95\% CI 0.98-1.47) (table 2). The increase was due primarily to a significant increase in "other nonmalignant respiratory diseases" (SMR 1.40, 95\% CI 1.04-1.84). When mortality from "other nonmalignant respiratory diseases" was examined by various indices of styrene exposure, it was found that the increase occurred among workers with a short length of exposure, low average exposure, or low cumulative exposure. As discussed in our previous reports $(6,7)$, the increase was probably not related to exposure to styrene, but more likely to the low socioeconomic class, smoking, or life-style factors characteristic of short-term workers. The observation that most of the deaths $(70 \%)$ from "other nonmalignant respiratory diseases" were chronic obstructive pulmonary diseases tended to confirm the role of cigarette smoking.

For pneumonia, specifically, in the US cohort we did not find any relationship with any of the exposure indices. The pneumonia SMR values were 0.98 and 0.47 for workers with $\geq 10.0$ years of exposure and $\geq 100.0 \mathrm{ppm}$ years of cumulative exposure, respectively. In terms of the average intensity of exposure, the SMR values were $1.16,0.61,0.95,0.93$, and 1.10 for $<5,5.0-9.9,10.0-$ $19.9,20.0-59.9$, and $\geq 60.0 \mathrm{ppm}$, respectively. None of the SMR values were significantly elevated, and there was no upward trend. Thus the pneumonia finding from the IARC study could not be confirmed in the US study.
Table 8. Analysis of selected causes of death based on the Cox proportional hazards model, with age, gender, cumulative exposure, duration of exposure, and average intensity of exposure to styrene as independent variables.

\begin{tabular}{lrrr}
\hline $\begin{array}{l}\text { Cause of death } \\
\text { (N) }\end{array}$ & $\begin{array}{c}\beta- \\
\text { coefficient }\end{array}$ & SD & P-value \\
\hline Diseases of the nervous system (N=14) & & & \\
$\quad$ Age (years) & 0.015 & 0.027 & 0.58 \\
Cumulative exposure (ppm-years) & 0.000 & 0.002 & 0.91 \\
$\quad$ Duration of exposure (years) & -0.009 & 0.050 & 0.86 \\
$\quad$ Average intensity of exposure (ppm) & -0.005 & 0.014 & 0.72 \\
Nonmalignant genitourinary diseases (N=13) & & & \\
Age (years) & 0.012 & 0.027 & 0.65 \\
Gender & -0.195 & 0.662 & 0.77 \\
Cumulative exposure (ppm-years) & 0.000 & 0.003 & 0.98 \\
Duration of exposure (years) & 0.067 & 0.050 & 0.19 \\
Average intensity of exposure (ppm) & -0.011 & 0.020 & 0.59 \\
Nonmalignant respiratory diseases (N=97) & & & \\
Age (years) & 0.088 & 0.009 & 0.00 \\
$\quad$ Gender & -0.938 & 0.300 & 0.00 \\
Cumulative exposure (ppm-years) & -0.001 & 0.001 & 0.66 \\
Duration of exposure (years) & -0.037 & 0.021 & 0.08 \\
Average intensity of exposure (ppm) & 0.002 & 0.054 & 0.77 \\
Pneumonia (N=23) & & & \\
Age (years) & 0.083 & 0.018 & 0.00 \\
Gender & -0.655 & 0.552 & 0.24 \\
Cumulative exposure (ppm-years) & -0.005 & 0.004 & 0.18 \\
Duration of exposure (years) & 0.004 & 0.047 & 0.94 \\
Average intensity of exposure (ppm) & 0.013 & 0.010 & 0.18 \\
\hline
\end{tabular}

Similarly, in the IARC study, Welp and her colleagues (4) reported that mortality from nonmalignant diseases of the genitourinary system increased with increasing average intensity of exposure. In the US cohort, there were only 13 deaths due to nonmalignant genitourinary diseases, slightly fewer than the 14.8 expected. When the data were examined by duration of exposure, cumulative exposure, or average intensity of exposure, no significantly elevated SMR values or upward trends were found. Therefore, the results of nonmalignant genitourinary diseases from the US cohort were not consistent with the findings reported by Welp et al (4) in the IARC study.

Of the 3 categories of diseases reported by Welp et al in 1996, it appears that these authors considered the finding of diseases of the nervous system much more definitive than the other 2 categories. They (5) stated that "Mortality from diseases of the central nervous system (27 deaths) increased with time since first exposure, duration of exposure, average level of exposure, and $\mathrm{cu}-$ mulative exposure to styrene [p 623]". However, the statistical tests conducted by Welp and her co-workers indicated that there was no significant upward trend for time since first exposure $\left(\mathrm{P}_{\text {trend }}=0.32\right)$ or average exposure $\left(\mathrm{P}_{\text {trend }}=0.37\right)$. Welp and her colleagues (5) also concluded that "Mortality from epilepsy increased monotonically with all styrene exposure indicators [p 623]". Again, the trend tests reported (5) indicated that there were no significant trends for average exposure 
$\left(P_{\text {trend }}=0.32\right)$ or cumulative exposure $\left(P_{\text {trend }}=0.07\right)$. On the other hand, the trend between mortality from epilepsy and time since first exposure was highly significant $\left(\mathrm{P}_{\text {trend }}=0.008\right)$, due to an extremely high risk ratio of 485.9 (95\% CI $1.19-9,999)$ based on only 1 observed death for the category "20 or more years after first exposure". Thus, except for epilepsy and time since first exposure, there was no significant upward trend in the exposureresponse analyses in the IARC study.

In the US cohort there was no increased mortality from diseases of the nervous system in general or from epilepsy in particular. When mortality was analyzed in relation to various indices of exposure to styrene, no pattern was found. For US workers with more than 10 years of styrene exposure, the SMR for diseases of the nervous system was 1.03 , and that for epilepsy was 0 (no epilepsy death occurred in the group). Similarly, in the US cohort, among persons with the highest cumulative exposure ( $\geq 100.0$ ppm-years), the SMR for diseases of the nervous system was 0.53 , and that for epilepsy was 0 . Thus data from the US cohort did not support the findings on mortality from diseases of the nervous system in the IARC study reported by Welp et al (5).

Thus the results between the IARC study and the US cohort were considerably different for diseases of the nervous system. In fact, the results for diseases of the nervous system were considerably different across countries within the IARC study. An 1994 internal IARC report provided a detailed mortality analysis by country (8). Of the 40 deaths due to central nervous system diseases, 30 were from Denmark ( $N=13$ ) or the United Kingdom $(\mathrm{N}=17)$, with the remaining 10 from Italy $(\mathrm{N}=3)$, Finland $(\mathrm{N}=1)$, Norway $(\mathrm{N}=3)$, and Sweden $(\mathrm{N}=3)$. Table $1-22$ in part III of the 1994 IARC report (8) shows that the SMR for central nervous system diseases for Denmark was $1.10(13 / 11.82)$ and that for the United Kingdom was 0.52 (17/32.57). The increase in Denmark could not have been explained by higher exposure since exposure levels in the United Kingdom were consistently higher than those in Denmark (figure 1 in reference 5). Furthermore, according to Welp et al (5), for central nervous system diseases "an inconsistently increasing risk by average exposure was observed in Denmark, while there was no increase in the other five countries [p 629]".

Mortality from central nervous system diseases or epilepsy has not been associated with chronic occupational exposures. On the other hand, persons with the following conditions are known to have a high risk of epilepsy: birth trauma (inadequate oxygen supply to the brain), perinatal infection, anoxia (postrespiratory or postcardiac arrest), infectious diseases (meningitis, encephalitis), inherited disorders or degenerative diseases (phenylketonuria or tuberous sclerosis), head injury or trauma, metabolic disorders (hyperglycemia or hypoparathyroidism), and cerebrovascular accident.
Unfortunately, none of these potential confounding risk factors were available for analysis in the IARC study. Alcohol consumption is a known risk factor of central nervous system diseases. The Danish cohort consisted of a disproportionally higher percentage of short-term workers. In the IARC study, 20 of the 28 deaths due to cirrhosis of the liver occurred among subjects with less than 1 year of employment (2). Thus alcohol consumption could have been a potential confounding factor among the Danish workers.

In summary, mortality from nonmalignant genitourinary diseases, nonmalignant respiratory diseases, and diseases of the nervous system among 15826 US workers exposed to styrene in the reinforced plastics and composites industry was examined in our investigation. We found no relationship between styrene exposure and any of these causes of death. The increased risks reported in the IARC study could not be replicated in our study. Apart from some of the reasons already discussed, there are at least 2 additional possible explanations for the observed discrepancies.

First, exposures among the US workers appeared to be lower than those among their European counterparts. More than $40 \%$ of the US workers were exposed to average levels below $10 \mathrm{ppm}$ (table 1). Only 14\% were exposed to average levels above $60 \mathrm{ppm}$. A great majority of the US workers were employed in the reinforced plastics and composites industry for a short period of time ( $70 \%$ for $<5$ years). Half of the US workers $(50 \%$ ) had cumulative exposures of less than 30 ppm-years. Only $24 \%$ of the US workers had cumulative exposures of more than 100 ppm-years. On the contrary, exposures in the IARC study appeared to be much higher. Although the number of workers were not reported, judging by the exposure categories used, it appeared that a considerable number of workers in the IARC study were exposed to average levels above $200 \mathrm{ppm}(3,4)$ and many accumulated more than 750 ppm-years (5). Thus exposure levels among the US workers might not have been high enough to produce the risks reported in the IARC study.

Second, the numbers of deaths in some of the analyses in the US study were small. For example, there were only 2 deaths each from epilepsy and nephritis. Even for the broader categories "diseases of the nervous system" and "nonmalignant genitourinary diseases," there were 14 and 13 deaths, respectively. The numbers were made even smaller in some of the subcohort analyses stratified by exposure category. The statistical power to detect a modest increase in risk was low in some of the analyses.

Therefore, in comparing the results between the US and the IARC studies, differences in exposure levels and statistical power between the 2 studies should be taken into consideration. Hopefully, future updates of the 2 studies and studies from other locations will provide further insights. 


\section{Acknowledgments}

The authors are grateful to the participating companies for providing the original cohort data, to the National Death Index of the National Center for Health Statistics for providing vital status information, to state health departments for providing copies of death certificates, and to the Styrene Information and Research Center for sponsoring the project.

\section{References}

1. Kogevinas M, Ferro G, Saracci R, Anderson A, Biocca M, Coggon D, et al. Cancer mortality in an international cohort of workers exposed to styrene. In: Sorsa M, Peltonen K, Vainio $\mathrm{H}$, Hemminki K, editors. Heath Hazards of butadiene and styrene. Lyon: International Agency for Research on Cancer, 1993.

2. Kogevinas M, Ferro G, Andersen A, Bellander T, Biocca M, Coggon D, et al. Cancer mortality in a historical cohort study of workers exposed to styrene. Scand J Work Environ Health 1994;20:251-61.
3. Welp E, Partanen T, Kogevinas M, Anderson A, Bellander T, Biocca M, et al. Exposure to styrene and mortality from nonmalignant respiratory diseases. Occup Environ Med 1996;53:499-501.

4. Welp E, Partanen T, Kogevinas M, Anderson A, Bellander T, Biocca M, et al. Exposure to styrene and mortality from nonmalignant diseases of the genitourinary system. Scand J Work Environ Health 1996;22:223-6.

5. Welp E, Kogevinas M, Andersen A, Bellander T, Biocca M Coggon D, et al. Exposure to styrene and mortality from nervous diseases and mental disorders. Am $\mathbf{J}$ Epidemiol 1996;144:623-33.

6. Wong $\mathrm{O}$. A cohort mortality study and a case-control study of workers potentially exposed to styrene in the reinforced plastics and composites industry. Br J Ind Med 1990;47:753-62.

7. Wong $\mathrm{O}$, Trent LS, Whorton MD. An updated mortality study of workers potentially exposed to styrene in the reinforced plastics and composites industry. Occup Environ Med 1994;51:386-96.

8. Kogevinas M, Ferro G, Saracci R, Anderson A, Bellander T, Biocca $\mathrm{M}$, et al. International Agency for Research on Cancer (IARC) historical multicentric cohort study of workers exposed to styrene: report of the epidemiological study and the industrial hygiene investigation. Lyon: IARC, 1994. IARC internal report 94/002.

Received for publication: 7 August 1998 